\title{
Methylation of Ecadherin gene is correlated with increased risk of nasopharyngeal carcinoma: A meta-analysis
}

Lao Duc Thuan ${ }^{1}$, Nguyen Thi Hoang Trinh ${ }^{1}$, Nguyen Thi Phuong Dieu ${ }^{1}$, Nguyen Thi Le ${ }^{1}$, Truong Kim Phuong ${ }^{1 *}$

${ }^{1}$ Ho Chi Minh City Open University, Vietnam

*Corresponding author: phuong.tk@ou.edu.vn

\section{ARTICLE INFO}

DOI: $10.46223 /$ HCMCOUJS. tech.en.9.1.349.2019

Received: April 6 ${ }^{\text {th }}, 2019$

Revised: May $7^{\text {th }}, 2019$

Accepted: May 21 $1^{\text {st }}, 2019$

Keywords:

DNA methylation, Ecadherin gene, meta - analysis, nasopharyngeal carcinoma

\section{ABSTRACT}

Background: The objective of this study was to estimate the correlation between E-cadherin $(\mathrm{CDH} 1)$ promoter methylation and the risk of nasopharyngeal cancer.

Methods: Based on previous online articles for the evaluation of the hypermethylated status of $\mathrm{CDH} 1$ gene at the promoter region with nasopharyngeal carcinoma, two independent reviewers selected studies through databases on PubMed, Google Scholar from 2001 to 2014. The software MedCalc ${ }^{\circledR}$ version 18.11 was applied for calculating pooled Odds Ratios (OR) with levels of data heterogeneity by the fixed and random effects models.

Results: Of a total of 99 articles, 12 studies with 508 clinical samples of nasopharyngeal carcinoma patients and 282 normal samples were selected in the systematic review for meta-analysis. Overall, the results demonstrated a highly significant association between $\mathrm{CDH} 1$ promoter methylation with nasopharyngeal carcinoma under the fixed effects model $(\mathrm{OR}=16.155,95 \% \mathrm{CI}$ : 8.533 - 30.585, $\mathrm{p}<0.001)$. The further subgroup analysis was conducted on types of samples, methods for detecting $\mathrm{CDH}$ methylation and patient ethnicity. In particularly, the results indicated the frequency of $\mathrm{CDHI}$ promoter methylation was significant higher in nasopharyngeal cancer samples than normal samples in Asia (OR = 15.879; 95\% CI: 7.28 - 34.608, p<0.001), Africa $(\mathrm{OR}=10.667 ; 95 \% \mathrm{CI}: 1.214-93.719, \mathrm{p}<0.001)$ and America $(\mathrm{OR}=3.9362$; 95\% CI: 0.1779 - 87.107, p>0.001).

Conclusion: This study proposed the strong association between $\mathrm{CDH1}$ promoter methylation and the risk of nasopharyngeal carcinoma in Asia and other populations. For this reason, the abnormal methylation in $\mathrm{CDH} 1$ gene should be a potential hallmark of prognosis and diagnosis for nasopharyngeal carcinoma. 


\section{Introduction}

There is generally well known that nasopharyngeal carcinoma (NPC) is one of EpsteinBar virus associated cancer (Lung, Cheng, \& Dai, 2014; Nasopharyngeal cancer statistics) and a head and neck cancer rare (Chou et al., 2008; Lung et al., 2014; Nasopharyngeal cancer statistics) which has the geographical distribution. The early cases of NPC were reported by Jackson (1901). According to WHO estimates for 2018, nasopharyngeal cancer as Nasopharyngeal Carcinoma (NPC) is the 24th most common cancer worldwide. There were about 129,079 new cases and 72,987 deaths from NPC in 2018. Globally, age-standardized incidence and mortality rates were over 1 case per 100,000 men, in contrast, less than 1 case per 100,000 women. NPC, although NPC is a rare malignancy in the world, was remarkable in some endemic areas of Southern China, Southeast Asia, North Africa and the Arctic. The highest incidence of NPC presented in five countries of Asia, including Malaysia, Singapore, Indonesia, Vietnam and Brunei, in 2012, China, Indonesia, Vietnam, India and Malaysia in 2018, respectively. NPC is the 6th most common cancer in Vietnam with 6212 new cases and 4232 deaths, respectively.

Das and Singal (2004), Luczak and Jagodziński (2006) and Kulis and Esteller (2010) indicated DNA methylation is an epigenetic mechanism that is categorized into hypermethylation and hypomethylation of Tumor Suppressor Genes (TSG) or proto-oncogenes. In addition, recent studies demonstrated a lot of evidence that DNA methylation profiles are associated with the risk of cancer diseases, typically nasopharyngeal carcinoma. Besides eating habit with large amounts of salt-preserved fish and meats, environmental exposures as dust and smoke, family history, EBV infection and genetic factors, especially in as DNA methylation plays the critical roles in the carcinogenesis of NPC.

Among the tumor suppressor genes, E-cadherin gene (CDH1) is located in a gene cluster of the cadherin family on chromosome 16 (16p22.1) and is composed of 16 exons. This gene encodes epithelial cadherin, a transmembrane glycoprotein that activates in the progress of cell adhesion, cell signal transduction, cell maturation and tissue organization. CDH1 gene was expressed mostly in the surfaces and cavities of the human body.

Up to date, numerous studies demonstrated a significant correlation between the methylated status of $\mathrm{CDHl}$ gene and the risk of developing nasopharyngeal cancer, however, the methylated frequencies of $\mathrm{CDH} 1$ gene promoter hypermethylation were significantly distinguishable. Particularly, the range of those values is estimated from $11 \%$ to $65 \%$. All of those conclusions and controversies depend on a variety of clinical characteristics of samples and molecular methods for identifying or quantifying DNA methylation in nasopharyngeal carcinoma. Therefore, this study has conducted a meta-analysis for evaluating in detail the correlation between $\mathrm{CDH} 1$ methylation and nasopharyngeal cancer progress.

\section{Materials and methods}

A systematic review was conducted by searching the primary research studies from PubMed, Google Scholar database, up to March 1, 2019. The search strategy is based on the various combinations of critical keywords: "CDH1"; "DNA methylation", "nasopharyngeal carcinoma" etc. 
The selection of published studies was performed by two independent reviewers with the inclusion and exclusion criteria. The inclusive data included (1) case control studies estimated the frequencies of $\mathrm{CDH} 1$ methylation in nasopharyngeal carcinoma and control samples; (2) the correct method for $\mathrm{CDH} 1$ methylation screening; (3) types of clinical samples include tissues as NPC primary tumor biopsies and blood; (4) English publications. The exclusion data consisted of (1) cohort or review studies; (2) studies that could not be calculated the original frequencies of $\mathrm{CDH} 1$ methylation; (3) unpublished and incomplete studies. Figure 1 illustrated a flow chart of the process for selecting studies.

Data extraction criteria described types of studies (case control or cohort), methods for detecting $C D H 1$ methylation, patient ethnicity, the frequencies of $C D H 1$ methylation and some clinicopathological characteristics of nasopharyngeal cancer.

The user-friendly, fast and reliable software as MedCalc ${ }^{\circledR}$ version 18.11 was applied for the statistical analysis as Cochran's Q $\chi^{2}$ statistic for calculating the Odd ratios (OR) with 95\% confidential intervals (CIs) in the fixed effects model (F) or the random effects model (R). In order to identify the suitable models, the $\mathrm{I}^{2}$ statistic test was performed to quantify the heterogeneity of data. The higher $\mathrm{I}^{2}$ values expressed the greater heterogeneity in the ranges from $50 \%$ to $100 \%$, so the best model was the random effects model and vice versa (The Cochrane Collaboration, 2011). 


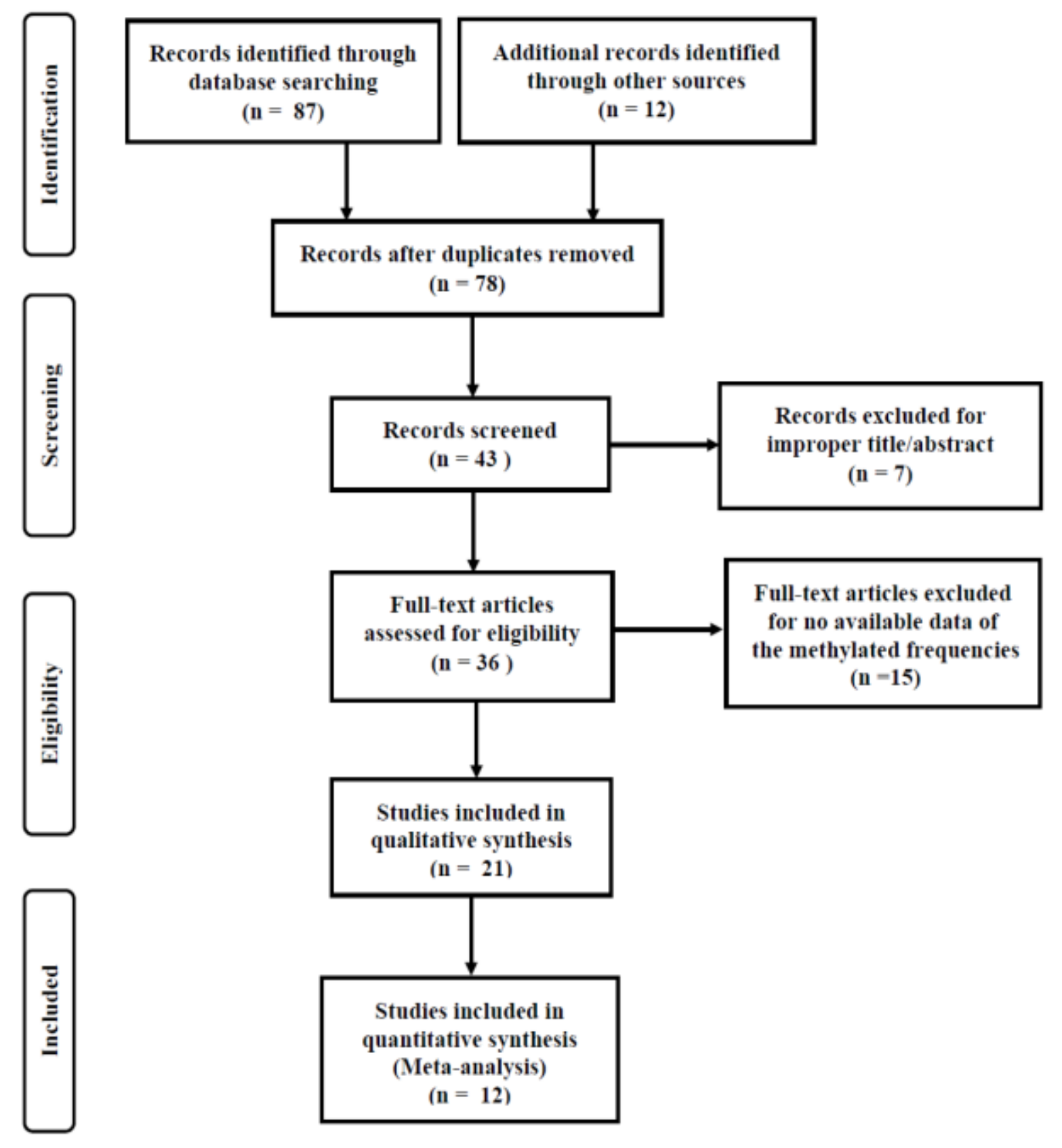

Figure 1. The flow chart of systematic review process

\section{Results}

\section{Study characteristics}

As shown in Figure 1 and Table 1, a total of 12 case control studies, including 508 nasopharyngeal carcinoma samples and 282 normal samples were evaluated for the status of CDH1 methylation. The subjects were conducted in three populations in Asia, Africa and America from 2001 to 2015. The number of studies that analyzed the status of CDH1 methylation in tissue samples as tumor biopsies, blood samples and others (MT: Mouth and throat rinsing fluid; BC: Buffy coat) was 11, 2 and 1, respectively (Table 1). 


\section{Table 1}

The eligibility studies in systematic review for the correlation between $\mathrm{CDH} 1$ methylation and NPC risk

\begin{tabular}{|c|c|c|c|c|c|c|c|c|}
\hline \multirow{2}{*}{$\begin{array}{c}\text { Studies } \\
\text { (First author, } \\
\text { Years) }\end{array}$} & \multirow[b]{2}{*}{ Nation } & \multirow[b]{2}{*}{ Ethnicity } & \multirow[b]{2}{*}{ Method } & \multirow{2}{*}{$\begin{array}{c}\text { Sample } \\
\text { Types }\end{array}$} & \multicolumn{2}{|c|}{ Case } & \multicolumn{2}{|c|}{ Control } \\
\hline & & & & & Events & Total & Events & Total \\
\hline $\begin{array}{l}\text { Asokan, Jeelani, } \\
\text { and } \\
\text { Gnanasundaram } \\
\text { (2014) }\end{array}$ & India & Asian & MSP & Tissue & 6 & 10 & 0 & 5 \\
\hline $\begin{array}{l}\text { Challouf et al. } \\
(2012)\end{array}$ & Tunisia & African & MSP & Tissue & 4 & 36 & 0 & 19 \\
\hline $\begin{array}{l}\text { Ran, Wu, } \\
\text { and You (2010) }\end{array}$ & China & Asian & MSP & Tissue & 13 & 20 & 0 & 5 \\
\hline $\begin{array}{l}\text { Niemhom, } \\
\text { Kitazawa, } \\
\text { Kitazawa, } \\
\text { Maeda, and } \\
\text { Leopairat (2008) }\end{array}$ & Japan & Asian & MSP & Tissue & 28 & 66 & 0 & 15 \\
\hline $\begin{array}{l}\text { Ayadi et al. } \\
(2008)\end{array}$ & Tunisia & African & MSP & Tissue & 35 & 44 & 0 & 3 \\
\hline $\begin{array}{l}\text { Sun, Zhang, } \\
\text { Huang, Ernberg, } \\
\text { and Hu (2007) }\end{array}$ & China & Asian & MSP & Tissue & 52 & 58 & 0 & 10 \\
\hline $\begin{array}{l}\text { Wong et al. } \\
\text { (2004) }\end{array}$ & China & Asian & QMSP & Tissue & 19 & 41 & 4 & 43 \\
\hline $\begin{array}{l}\text { Wong et al. } \\
\text { (2003) }\end{array}$ & China & Asian & MSP & Blood & 15 & 30 & 0 & 5 \\
\hline $\begin{array}{l}\text { Tsao et al. } \\
(2003)\end{array}$ & China & Asian & MSP & Tissue & 15 & 29 & 1 & 15 \\
\hline $\begin{array}{l}\text { Chang et al. } \\
\text { (2003) }\end{array}$ & China & Asian & MSP & Tissue & 16 & 30 & 0 & 6 \\
\hline $\begin{array}{l}\text { Chang et al. } \\
\text { (2003) }\end{array}$ & China & Asian & MSP & Blood & 2 & 30 & 0 & 43 \\
\hline
\end{tabular}




\begin{tabular}{|l|c|c|c|c|c|c|c|c|}
\hline \multirow{2}{*}{$\begin{array}{c}\text { Studies } \\
\text { (First author, } \\
\text { Years) }\end{array}$} & Nation & Ethnicity & Method & $\begin{array}{c}\text { Sample } \\
\text { Types }\end{array}$ & Events & Total & Events & Total \\
\hline $\begin{array}{l}\text { Chang et al. } \\
(2003)\end{array}$ & China & Asian & MSP & (MT) & 8 & 30 & 0 & 37 \\
\hline $\begin{array}{l}\text { Chang et al. } \\
(2003)\end{array}$ & China & Asian & MSP & (BC) & 13 & 30 & 0 & 43 \\
\hline $\begin{array}{l}\text { Corn et al. } \\
(2001)\end{array}$ & USA & American & NMSP & Tissue & 26 & 31 & 6 & 31 \\
\hline $\begin{array}{l}\text { Nakayama et al. } \\
(2001)\end{array}$ & USA & American & MSP & Tissue & 18 & 23 & 0 & 2 \\
\hline
\end{tabular}

Note: (MT): Mouth and throat rinsing fluid; (BC): Buffy coat

Source: The researcher's data analysis

\section{CDH1 methylation and NPC risk}

The key results for Chi-square statistic and heterogeneity test are illustrated in Figure 2 and Figure 3. With the exclusion of the same article of Chang et al. (2003), a pooled odds ratio $(\mathrm{OR})$ as the overall index was calculated at $16.155(\mathrm{OR}=16.155,95 \% \mathrm{CI}: 8.533-30.585$, $\mathrm{p}<0.001$ ) in the fixed effects model, in which the number of clinical samples of NPC and normal samples were 418 and 159 , respectively. It is clearly shown that the frequency of $C D H 1$ methylation in NPC samples was twelve times higher than in controls, in other words, the increasing of NPC risk was associated with $\mathrm{CDH} 1$ hypermethylation.

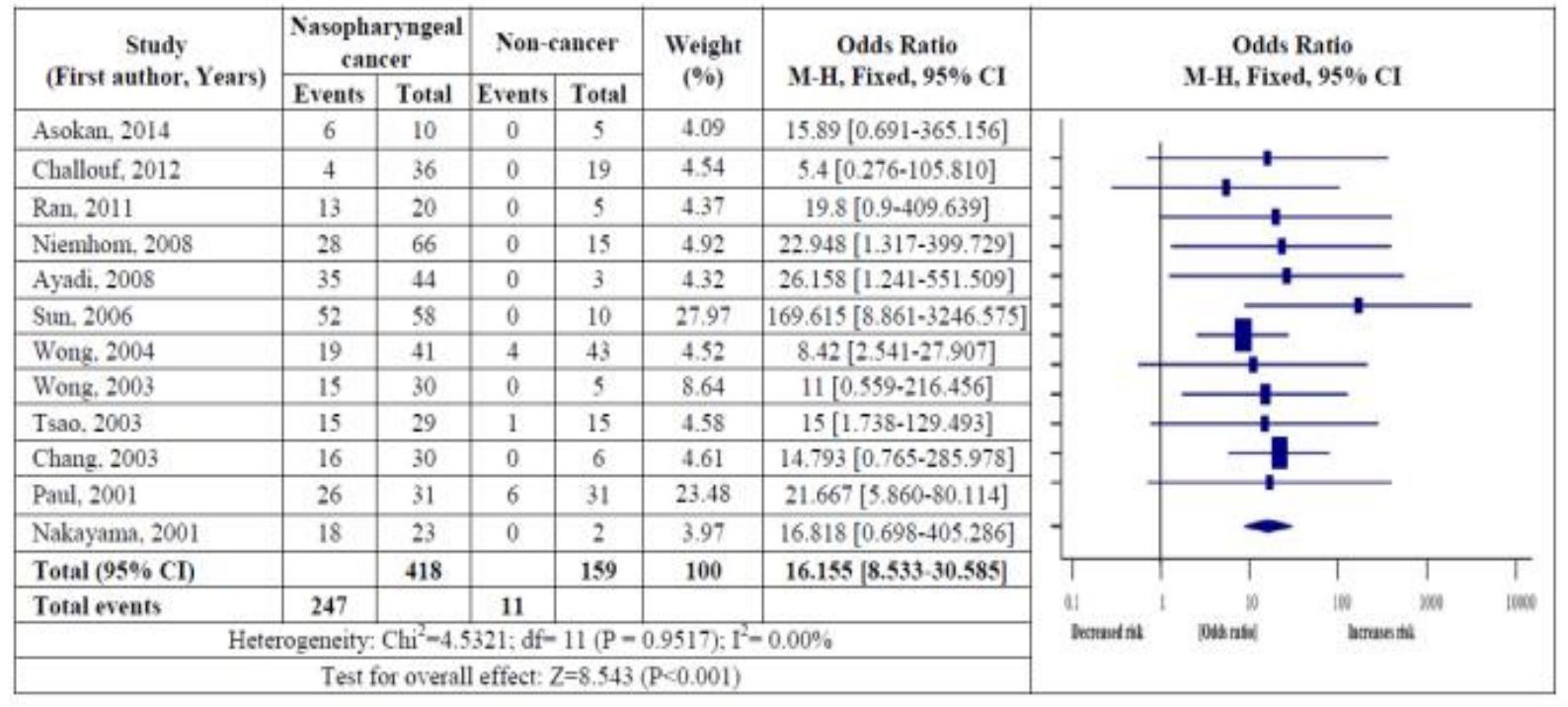

Figure 2. Forest plot of the correlation between $C D H 1$ methylation and NPC risk 


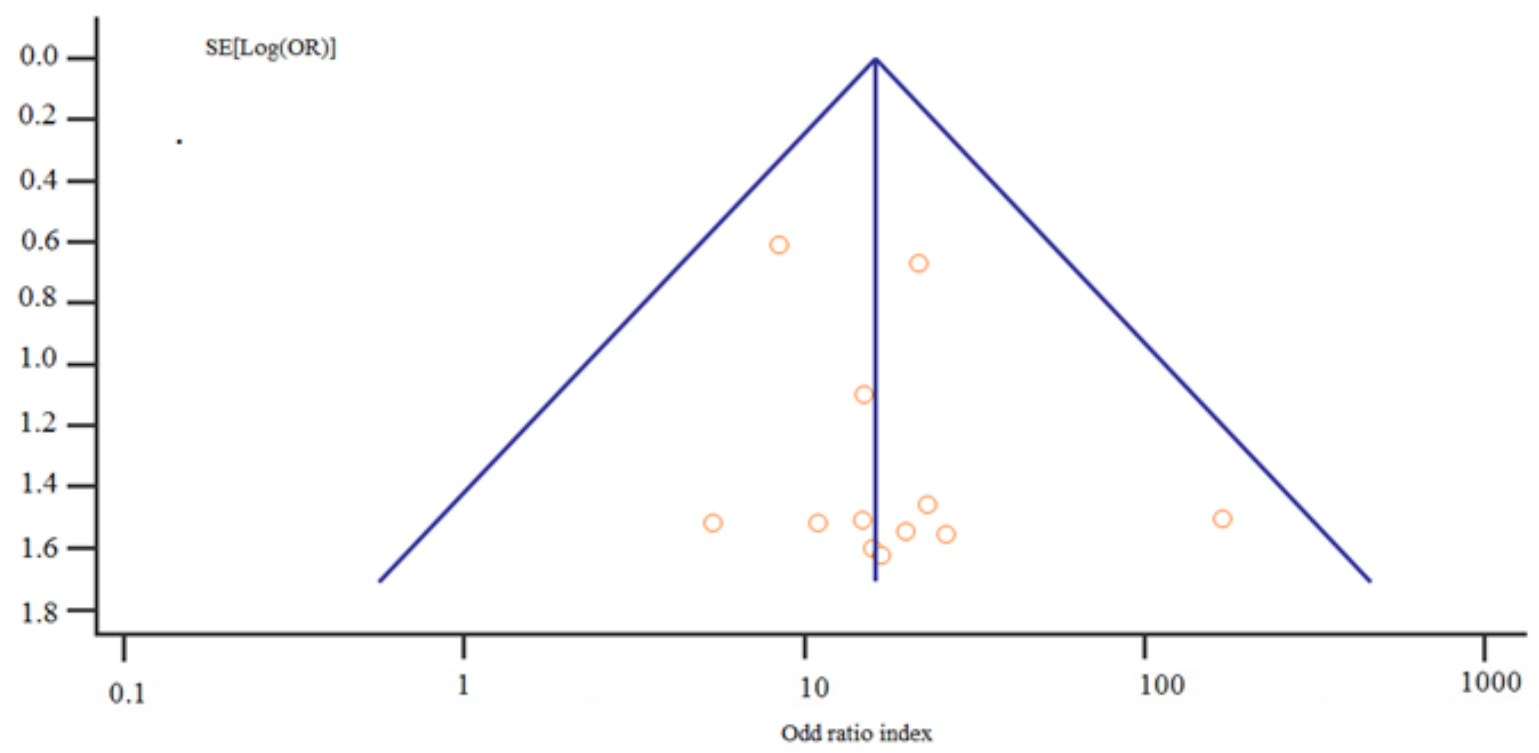

Figure 3. Funnel plot for the evaluating publication bias for the correlation between $C D H 1$ methylation and NPC risk

Note: The standard error of $\log [\mathrm{OR}]$ of each study was plotted against its $\log [\mathrm{OR}]$

For investigating the publication bias of studies included in this meta-analysis, the funnel plot was performed (Figure 3), but the publication bias test was not carried out by Begg's funnel plot and Egger's test. The results indicated the publication bias could present because of the asymmetrical funnel plot (Figure 3). Additionally, the inconsistent results due to the specific data which were mentioned in the materials and method section and Figure 2. Consequently, subgroup analyses were carried out for further investigation in the relation between $C D H 1$ methylation and those critical categories, including $\mathrm{CDH} 1$ methylation analysis methods, the population of NPC patients some histopathological characteristics of NPC. The results are shown in Table 2.

\section{Table 2}

Overall and subgroup analyses for the correlation between $\mathrm{CDH} 1$ methylation and NPC risk in case-control studies

\begin{tabular}{|l|c|c|c|c|c|c|c|}
\hline & \multicolumn{4}{|c|}{ Test of associations } & \multicolumn{3}{c|}{ Test of heterogeneity } \\
\hline Variables & N & OR $(95 \% \mathrm{CI})$ & $\mathrm{Z}$ & P value & Mode & $\mathrm{P}_{\mathrm{H}}$ & $\mathrm{I}^{2}(\%)$ \\
\hline Total & $\mathbf{1 2}$ & $\mathbf{1 6 . 1 5 5}[\mathbf{8 . 5 3 3} \mathbf{- 3 0 . 5 8 5 ]}$ & $\mathbf{8 . 5 4 3}$ & $<\mathbf{0 . 0 0 1}$ & F & $\mathbf{0 . 9 5 1 7}$ & $\mathbf{0}$ \\
\hline Methods & \multicolumn{7}{|l|}{} \\
\hline MSP & $\mathbf{1 0}$ & $\mathbf{1 9 . 2 5 8}[7.742-\mathbf{4 7 . 9 0 4}]$ & $\mathbf{6 . 3 6 2}$ & $<\mathbf{0 . 0 0 1}$ & F & $\mathbf{0 . 9 6 1 0}$ & $\mathbf{0}$ \\
\hline Other & 2 & $12.606[5.204-30.535]$ & 5.614 & $<0.001$ & F & 0.2954 & 8.65 \\
\hline
\end{tabular}




\begin{tabular}{|c|c|c|c|c|c|c|c|}
\hline & & \multicolumn{3}{|c|}{ Test of associations } & \multicolumn{3}{|c|}{ Test of heterogeneity } \\
\hline \multicolumn{8}{|l|}{ Ethnicity } \\
\hline Asian & 8 & $15.879[7.286-34.608]$ & 6.956 & $<0.001$ & $\mathbf{F}$ & 0.8139 & $\mathbf{0}$ \\
\hline African & 2 & $10.667[1.214-93.719]$ & 2.135 & 0.033 & $\mathrm{~F}$ & 0.4651 & 0 \\
\hline American & 1 & $3.9362[0.1779-87.107]$ & 0.867 & 0.3858 & $\mathrm{Na}$ & $\mathrm{Na}$ & $\mathrm{Na}$ \\
\hline \multicolumn{8}{|c|}{ Sample types } \\
\hline Tissue & 10 & $19.258[7.742-47.904]$ & 6.362 & $<0.001$ & $\mathbf{F}$ & 0.9610 & $\mathbf{0}$ \\
\hline Others & 1 & $29.592[5.690-153.891]$ & 4.027 & $<0.001$ & $\mathrm{~F}$ & 0.5888 & 0 \\
\hline \multicolumn{8}{|c|}{ Pathological characteristics } \\
\hline Age & 5 & $1.487[0.653-3.386]$ & 0.945 & 0.345 & $\mathrm{~F}$ & 0.6979 & 0 \\
\hline Stage & 4 & $1.86[0.856-4.041]$ & 1.567 & 0.117 & $\mathrm{~F}$ & 0.3020 & 17.78 \\
\hline
\end{tabular}

Note: $\mathrm{Na}$ (Non analysis)

Source: The researcher's data analysis

Ethnicity-based subgroup analyses (Table 2) showed that significantly higher frequency of $C D H 1$ methylations in NPC cases than controls in both Asian (OR $=15.879$; 95\% CI: 7.286 - 34.608, $\mathrm{p}<0.001)$ by the fixed effects models with between-study homogeneity in 8 independence studies (Figure 4) and African (OR = 10.667; 95\% CI: 1.214 - 93.719, p<0.001) by the fixed effects models with between-study homogeneity in 2 studies, while in American $(\mathrm{OR}=3.9362 ; 95 \% \mathrm{CI}: 0.1779-87.107, \mathrm{p}>0.001)$ in only one study, respectively.

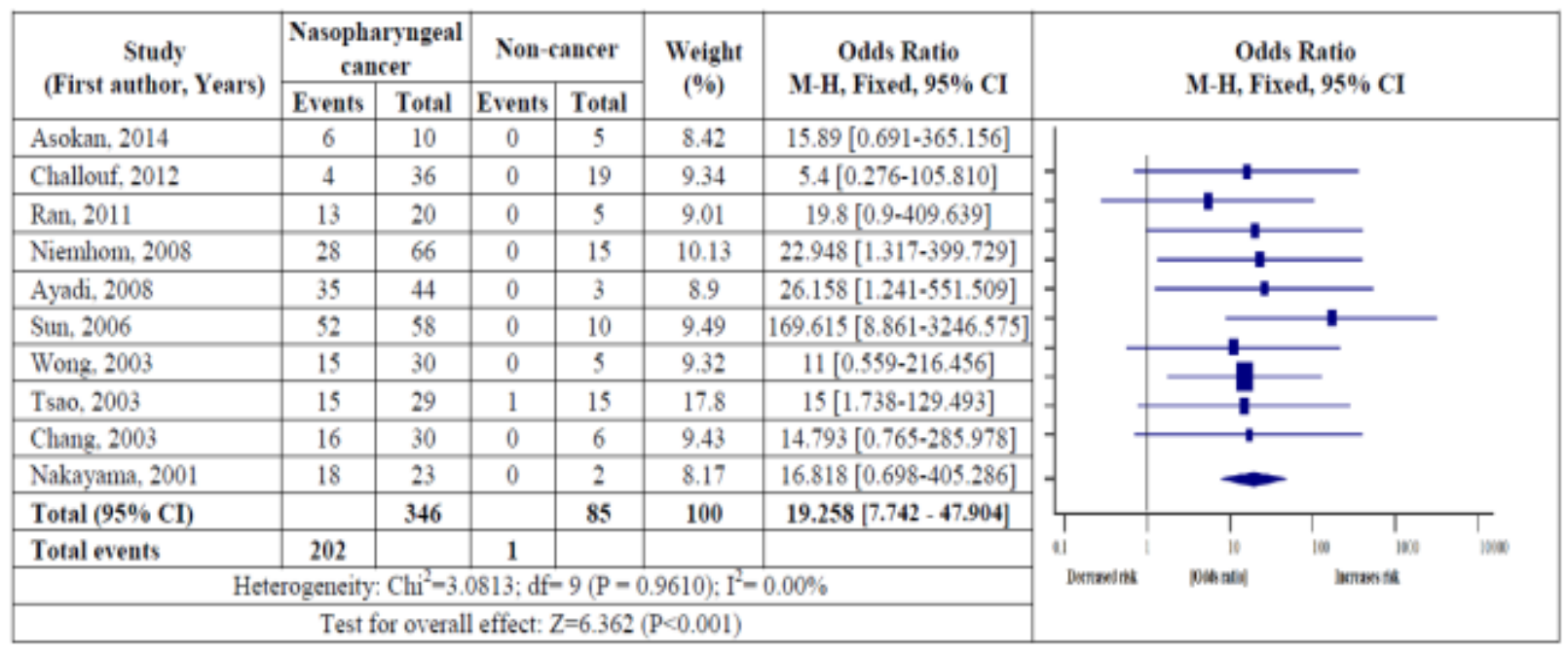

Figure 4. Forest plot of the correlation between $\mathrm{CDH1}$ methylation and NPC risk in Asian 


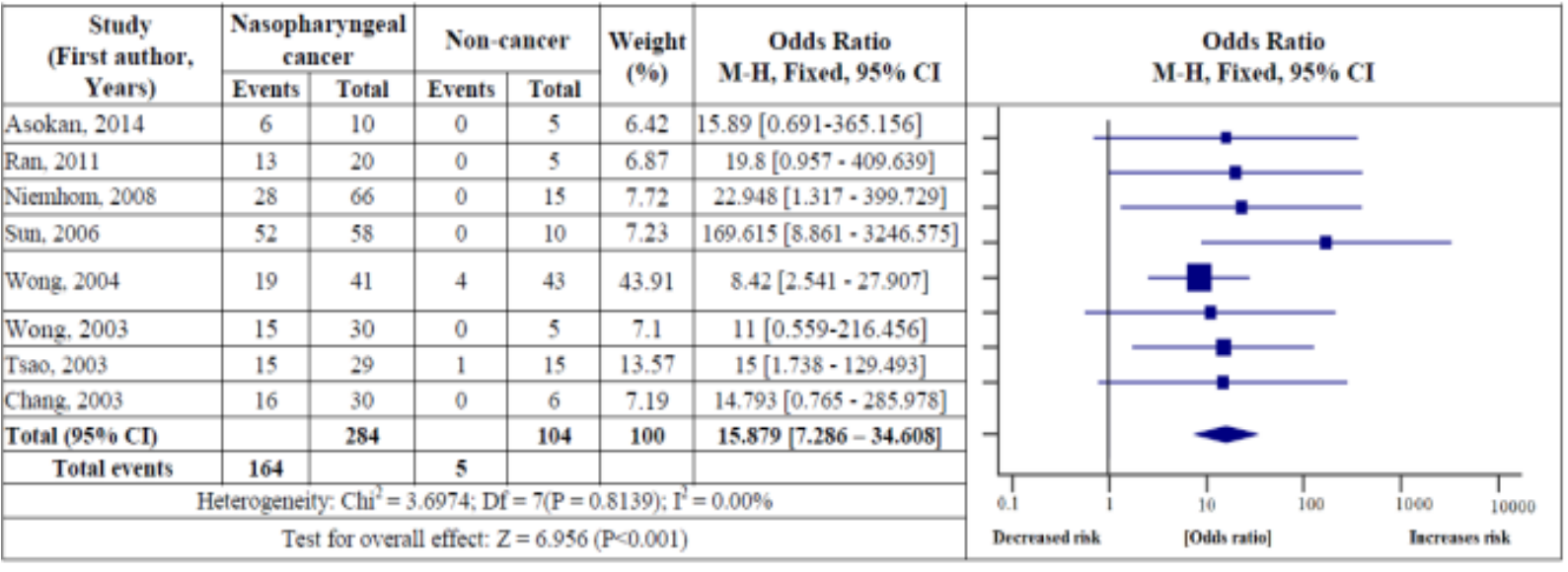

Figure 5. Forest plot of the correlation between $C D H 1$ methylation and NPC risk in MSP/NMSP or tissues based subgroup analysis

CDH1 methylation methods-based subgroup analysis was performed by the categories of MSP (Methylated specific PCR) and NMSP (Nested-MSP) in 10 studies and others including qMSP (Quantitative methylation-specific PCR) and QRT (Real-time quantitative polymerase chain reaction) in 2 studies, respectively. Hence, the results indicate MSP and Nested-MSP are common methods for analyzing the status of $\mathrm{CDH} 1$ methylation. Eventually, by using MSP or NMSP, CDH1 methylation frequency in NPC patients were calculated over 19 times higher than in healthy human volunteers $(\mathrm{OR}=19.258,95 \% \mathrm{CI}: 7.742-47.904, \mathrm{p}<0.001)$ by the fixed effects models, data were shown in Table $2 \&$ Figure 5.

Results of the sample types - based subgroup analyses (Table 2; Figure 5) implied the significant difference $(\mathrm{p}<0.05)$ in $\mathrm{CDH} 1$ hypermethylation level between cancer samples and normal samples. OR value was calculated by the fixed effects models in tissues $(\mathrm{OR}=19.258$, 95\% CI: 7.742 - 47.904) and other samples, including blood, mouth and throat rinsing fluid and buffy coat $(\mathrm{OR}=29.592,95 \%$ CI: $5.690-153.891)$ in the study of Chang et al. (2003), respectively.

In the clinicopathological characteristics of nasopharyngeal cancer, a total of seven and four studies were selected for the evaluation of $\mathrm{CDH} 1$ methylation in late age versus early age and late-stage versus early - stage, respectively. The pooled analysis showed that there was no significant association between $C D H 1$ methylation and age of NPC patients or tumor-stage by the fixed effects models (Table 2).

\section{Discussions}

Despite a meta-analysis of $\mathrm{C}$. Wu et al. (2018) was carried out for evaluating the association between E-cadherin gene promoter methylation and the risk of NPC with ten published studies, our meta-analysis was conducted by the combination of twelve independent studies in order to reveal the correlation between the aberrant DNA methylation in the CDH1 gene promoter region and the risk of NPC. Particularly, the overall OR of CDH1 methylation in NPC samples versus normal samples was 16.155 (OR $=16.155,95 \%$ CI: $8.533-30.585$, p $<0.001)$. These results implied a strong correlation between $C D H 1$ hypermethylation and nasopharyngeal cancer. 
In addition, all of the subgroup analyses indicated significant evidence of the relation between NPC clinical samples and the risk of NPC. Remarkably, subgroup meta-analysis on geographical populations as ethnicity showed that $C D H 1$ hypermethylation was a significant risk factor of NPC patients by Odds ratio in decreasing order for Asian, African, and American population $(\mathrm{OR}=15.879 ; \mathrm{OR}=10.667 ; \mathrm{OR}=3.9362$, respectively). In a way, a meta-analysis of C. Wu et al. (2018) inferred from previous data that was a relatively more frequency of $C D H 1$ methylation in NPC population in Asia than Africa ( $O R=16.98$ vs $O R=10.67)$. Likewise, data of WHO, Salehiniya, Mohammadian, Mohammadian-Hafshejani, and Mahdavifar (2018) and C. Wu et al. (2018) showed that NPC has the characterized geographical distribution with more frequency of new cases that occurred in Asia than Africa ( $81 \%$ vs 9\%). Thus, the aberrant DNA methylation of $\mathrm{CDH} 1$ gene might become a potential biomarker for the prediction, prognosis and early detection of NPC in Asia, especially in Vietnam.

Besides, subgroup meta-analysis on sample types illustrated OR of NPC samples in comparison with normal samples, in detail, OR value was higher in tissues than other types (OR $=11.442$ vs OR = 12.606). However, there was a higher OR $(29.592,95 \%$ CI: 5.690 - 153.891) in blood, mouth and throat rinsing fluid and buffy coat which were only used in the research of Chang et al. (2003). In contrast, tissues and blood were analyzed in 11 studies and 2 studies, respectively. Thereby, that evidence showed that tissue or blood should be the common, efficient clinical samples in testing the CHD1 methylation for diagnosis of NPC.

Previously, C. Wu et al. (2018) showed that no significant association between the status of $\mathrm{CDH1}$ methylation and some clinicopathological characteristics in NPC, for example, sex or age, EBV infection, pathological types, tumor sizes, lymph nodes, metastatic status, and clinical stage in patients with NPC. Definitely, our analyses have suggested the same evidence of no significant relationship between $C D H 1$ methylation and age or tumor stage of NPC. In fact, the reasonable explanation should be due to a lack of data and $\mathrm{CDH} 1$ methylation may be an early molecular event without age-dependent in the progress of NPC which are closely related to EBV infection.

This meta-analysis had a few of these limitations that should be considered: (1) because most of those included studies written in English, publication bias exited by languages selection; (2) a total of twelve articles were case control studies; (3) the heterogeneity of the databases may express due to the differences in NPC population, methods of detecting DNA methylation, types of cancer or normal samples; (4) there was the lack of sufficient data for evaluating the associations between the $C D H 1$ methylation and the confounding factors of NPC, for example, lifestyle, eating habit or diet and the main clinicopathological characteristics of NPC, including EBV infection, pathological types, tumor sizes, lymph node, metastatic status; (6) there was less than ten studies in subgroup meta-analyses, so should not have sufficient statistical power for evaluating the association of the $\mathrm{CDH} 1$ methylation and the risk of NPC in each criterion.

Otherwise, this meta-analysis was performed with database updates in the process of the systematic review. In addition, subgroup analysis was conducted for estimating the relation of the $\mathrm{CDH} 1$ methylation and NPC risk that were featured in the ethnicity of NPC patients, sample types, methods of DNA methylation analysis. Eventually, the current study found the most useful evidence for the analysis of the association between $C D H 1$ methylation and NPC. 


\section{Conclusions}

In conclusion, the results reveal a strong association between $C D H 1$ promoter methylation and nasopharyngeal cancer risk. Furthermore, it is obvious that $C D H 1$ promoter is proved to be a promising potential biomarker for the risk prediction, prognosis and diagnosis of NPC as the hallmark of poor overall survival of this type of cancer. The study had limitations that were no statistically significant differences in the status of $C D H 1$ methylation between subgroups of ages and tumor-stages in NPC patient population. As a result, a meta-analysis can be conducted in future studies which have a large scale of studies as well as the increasing number of case and control samples and full data of the clinicopathological characteristics.

\section{ACKNOWLEDGMENTS}

The authors would like to express our thanks to Ho Chi Minh City Open University (HCMOU) for the financial supporting of the study of lectures (No. E2018.02.1) and a study of students (No.38) at Faculty of Biotechnology (HCMOU).

The authors would like to thank Assoc. Prof. Dr. Le Huyen Ai Thuy for her effective supervision on research methodology and her special encouragement in writing this manuscript.

\section{References}

Asokan, G. S., Jeelani, S., \& Gnanasundaram, N. (2014). Promoter hypermethylation profile of tumour suppressor genes in oral leukoplakia and oral squamous cell carcinoma. Journal of Clinical and Diagnostic Research: JCDR, 8(10), ZC09-ZC12.

Ayadi, W., Karray-Hakim, H., Khabir, A., Feki, L., Charfi, S., Boudawara, T., ... Hammami, A. (2008). Aberrant methylation of p16, DLEC1, BLU and E-cadherin gene promoters in nasopharyngeal carcinoma biopsies from Tunisian patients. Anticancer Research, 28(4B), 2161-2167.

Bray, F., Ferlay, J., Soerjomataram, I., Siegel, R. L., Torre, L. A., \& Jemal, A. (2018). Global cancer statistics 2018: GLOBOCAN estimates of incidence and mortality worldwide for 36 cancers in 185 countries. CA: A Cancer Journal for Clinicians, 68(6), 394-424.

Cancer Today. (2018). Data visualization tools for exploring the global cancer burden in 2018. Retrieved March 12, 2019, from https://gco.iarc.fr/today/fact-sheets-cancers

Carioli, G., Negri, E., Kawakita, D., Garavello, W., La Vecchia, C., \& Malvezzi, M. (2017). Global trends in nasopharyngeal cancer mortality since 1970 and predictions for 2020: Focus on low-risk areas. International Journal of Cancer, 140(10), 2256-2264.

Challouf, S., Ziadi, S., Zaghdoudi, R., Ksiaa, F., Gacem, R. B., \& Trimeche, M. (2012). Patterns of aberrant DNA hypermethylation in nasopharyngeal carcinoma in Tunisian patients. Clinica Chimica Acta, 413(7/8), 795-802.

Chang, H. W., Chan, A., Kwong, D. L. W., Wei, W. I., Sham, J. S. T., \& Yuen, A. P. W. (2003). Evaluation of hypermethylated tumor suppressor genes as tumor markers in mouth and throat rinsing fluid, nasopharyngeal swab and peripheral blood of nasopharygeal carcinoma patient. International Journal of Cancer, 105(6), 851-855. 
Chou, J., Lin, Y. C., Kim, J., You, L., Xu, Z., He, B., \& Jablons, D. M. (2008). Nasopharyngeal carcinoma - Review of the molecular mechanisms of tumorigenesis. Head \& Neck: Journal for the Sciences and Specialties of the Head and Neck, 30(7), 946-963.

Corn, P. G., Heath, E. I., Heitmiller, R., Fogt, F., Forastiere, A. A., Herman, J. G., \& Wu, T. T. (2001). Frequent hypermethylation of the 5' $\mathrm{CpG}$ island of E-cadherin in esophageal adenocarcinoma. Clinical Cancer Research, 7(9), 2765-2769.

Das, P. M., \& Singal, R. (2004). DNA methylation and cancer. Journal of Clinical Oncology, 22(22), 4632-4642.

Jackson, C. (1901). Primary carcinoma of the naso-pharynx. A table of cases. Transactions of the Section on Laryngology and Otology of the American Medical Association, 125.

Jiang, W., Cai, R., \& Chen, Q. Q. (2015). DNA methylation biomarkers for nasopharyngeal carcinoma: Diagnostic and prognostic tools. Asian Pacific Journal of Cancer Prevention, 16(18), 8059-8065.

Jin, Z., \& Liu, Y. (2018). DNA methylation in human diseases. Genes \& Diseases, 5(1), 1-8.

Kulis, M., \& Esteller, M. (2010). DNA methylation and cancer. In Advances in genetics (pp. 27-56). Cambridge, MA: Academic Press.

Luczak, M. W., \& Jagodziński, P. P. (2006). The role of DNA methylation in cancer development. Folia Histochemica et Cytobiologica, 44(3), 143-154.

Lung, H. L., Cheng, Y., \& Dai, W. (2014). The interplay of host genetic factors and EpsteinBarr virus in the development of nasopharyngeal carcinoma. Chinese Journal of Cancer, 33(11), 556-568.

Mahdavifar, N.,Gho ncheh, M., Mohammadian-Hafshejani, A., \& Khosravi, ～B. (2016). Epidemiology and inequality in the incidence and mortality of nasopharynx cancer in Asia. Osong Public Health and Research Perspectives, 7(6), 360-372.

Medline Plus. (2019). CDH1 gene. Retrieved March 14, 2019, from https://ghr.nlm.nih.gov/gene/CDH1

Mikeska, T., \& Craig, J. (2014). DNA methylation biomarkers: Cancer and beyond. Genes, $5(3), 821-864$.

Moher, D., Liberati, A., Tetzlaff, J., \& Altman, D. G. (2009). Preferred reporting items for systematic reviews and meta-analyses: The PRISMA statement. Annals of Internal Medicine, 151(4), 264-269.

Nakayama, S., Sasaki, A., Mese, H., Alcalde, R. E., Tsuji, T., \& Matsumura, T. (2001). The Ecadherin gene is silenced by $\mathrm{CpG}$ methylation in human oral squamous cell carcinomas. International Journal of Cancer, 93(5), 667-673.

NCBI. (2019). CDH1 cadherin 1. Retrieved March 13, 2019, from https://www.ncbi.nlm.nih.gov/gene/999)

Niemhom, S., Kitazawa, S., Kitazawa, R., Maeda, S., \& Leopairat, J. (2008). Hypermethylation of epithelial-cadherin gene promoter is associated with Epstein-Barr virus in nasopharyngeal carcinoma. Cancer Detection and Prevention, 32(2), 127-134.

Pećina-Šlaus, N. (2003). Tumor suppressor gene E-cadherin and its role in normal and malignant cells. Cancer Cell International, 3(1), 1-7. 
Ran, Y., Wu, S., \& You, Y. (2010). Demethylation of E-cadherin gene in nasopharyngeal carcinoma could serve as a potential therapeutic strategy. The Journal of Biochemistry, $149(1), 49-54$.

Salehiniya, H., Mohammadian, M., Mohammadian-Hafshejani, A., \& Mahdavifar, N. (2018) Nasopharyngeal cancer in the world: Epidemiology, incidence, mortality and risk factors. World Cancer Research Journal, 5(1), 1-8.

Sun, D., Zhang, Z., Huang, G., Ernberg, I., \& Hu, L. (2007). Aberrant methylation of CDH13 gene in nasopharyngeal carcinoma could serve as a potential diagnostic biomarker. Oral Oncology, 43(1), 82-87.

The Cochrane Collaboration. (2011). Cochrane handbook for systematic reviews of interventions. Retrieved March 15, 2019, from http://handbook-5-1.cochrane.org

Thuan, D. L., Thuy, A. H. L., Chuong, H. N., Kha, D. N., Hue, H. T., Dung, H. N., \& Trong, M. N. (2017). In silico analysis of hypermethylation of E-cadherin gene promoter in nasopharyngeal carcinoma. Journal of Science, 7(2), 22-29.

Tsao, S. W., Liu, Y., Wang, X., Yuen, P. W., Leung, S. Y., Yuen, S. T., ... Wong, Y. C. (2003). The association of E-cadherin expression and the methylation status of the E-cadherin gene in nasopharyngeal carcinoma cells. European Journal of Cancer, 39(4), 524-531.

UICC. (2018). New global cancer data: GLOBOCAN 2018. Retrieved March 17, 2019, from https://www.uicc.org/new-global-cancer-data-globocan-2018

Wong, T. S., Kwong, D. L. W., Sham, J. S. T., Wei, W. I., Kwong, Y. L., \& Yuen, A. P. W. (2004). Quantitative plasma hypermethylated DNA markers of undifferentiated nasopharyngeal carcinoma. Clinical Cancer Research, 10(7), 2401-2406.

Wong, T. S., Tang, K. C., Kwong, D. L. W., Sham, J. S. T., Wei, W. I., Kwong, Y. L., \& Yuen, A. P. W. (2003). Differential gene methylation in undifferentiated nasopharyngeal carcinoma. International Journal of Oncology, 22(4), 869-874.

World Cancer Research Fund. (2018). Nasopharyngeal cancer statistics. Nasopharyngeal cancer is the 23rd most common cancer worldwide. Retrieved March 16, 2019, from https://www.wcrf.org/dietandcancer/cancer-trends/nasopharyngeal-cancer-statistics

Wu, C., Peng, S., Sun, W., Luo, M., Su, B., Liu, D., \& Hu, G. (2018). Association of E-cadherin methylation with risk of nasopharyngeal cancer: A meta-analysis. Head \& Neck, 40(11), 2538-2545.

Wu, L., Li, C., \& Pan, L. (2018). Nasopharyngeal carcinoma: A review of current updates. Experimental and Therapeutic Medicine, 15(4), 3687-3692. 